\title{
MARX, MAQUINARIA E GRANDE INDÚSTRIA: O DESENVOLVIMENTO TECNOLÓGICO NO LIVRO I DE DAS KAPITAL *
}

\author{
Paulo Fernando Rocha Antunes ** \\ Faculdade de Letras da Universidade de Lisboa (FLUL) \\ (D) https://orcid.org/0000-0002-3603-0127
}

\section{RESUMO:}

O presente trabalho recupera a reflexão de Marx, acerca do desenvolvimento tecnológico, com base no seu famoso $13 .^{\circ}$ capítulo "Maquinaria e grande indústria" (Maschinerie und große Industrie), pertencente ao Livro I de Das Kapital. Ao longo deste trabalho serão sucintamente analisadas questões fundamentais como a da acumulação de capital, a concorrência e a compulsão (capitalista) por mais-valia (absoluta e relativa), o papel da luta de classes face a isto e a maneira como as relações sociais (de produção) vigentes influenciam o desenvolvimento tecnológico. No final destrinçam-se as contradições da tecnologia dadas as relações sociais de produção capitalistas.

PALAVRAS-CHAVE: Capital; Concorrência; Luta de classes; Mais-valia; Tecnologia.

\section{MARX, MACHINERY AND LARGE INDUSTRY: THE TECHNOLOGICAL DEVELOPMENT IN BOOK I OF DAS KAPITAL}

\begin{abstract}
:
The present work recovers Marx's thought on technological development, from his famous 13th chapter "Machinery and large industry" (Maschinerie und große Industrie), which belongs to Book I of Das Kapital. Throughout this work, fundamental questions such as capital accumulation, competition and (capitalist) compulsion for surplus value (absolute and relative), the role of class struggle in this respect and how social relations (of production) influence the technological development will be succinctly analyzed. In the end, the contradictions of technology are revealed given the capitalist social relations of production.
\end{abstract}

KEYWORDS: Capital; Competition; Class struggle; Surplus-value; Technology.

\footnotetext{
** Doutorando em Filosofia Política Contemporânea pelo Programa de pós-graduação da Faculdade de Letras da Universidade de Lisboa (FLUL), Portugal. Bolseiro da Fundação para a Ciência e a Tecnologia (FCT), apoiado pelo orçamento comunitário através do FSE. Membro do Centro de Filosofia da Universidade de Lisboa (CFUL) integrado no Grupo de investigação PRAXIS e Núcleo de Estudos Políticos da Universidade de Lisboa (nepUL). Membro do Grupo de Estudos Marxistas (GEM). E-mail: pauloantunes@campus.ul.pt.
}

ANTUNES, Paulo Fernando Rocha. Marx, maquinaria e grande indústria: o desenvolvimento tecnológico no Livro I de Das Kapital. Griot : Revista de Filosofia, Amargosa, Bahia, v.16, n.2, p.36-55, dezembro/2017. 36 
Uma história crítica da tecnologia comprovaria em geral quão pouco qualquer invenção do século XVIII pertence a um único indivíduo. Até hoje [ao tempo em que Marx escrevia O Capital] não existe uma tal obra. Marx, 1867.

[...] é fundamental retomar a reflexão de Marx sobre as máquinas e sobre o desenvolvimento da grande indústria, contida no décimo terceiro capítulo de $\mathrm{O}$ Capital. Com efeito, esta é uma das partes da obra de maior interesse atual, quer porque demonstra capacidades de previsão extraordinárias - o Livro Primeiro foi publicado em 1867 - sobre as dinâmicas sociais que atuam de forma ainda mais completa na fase histórica em curso, quer sobretudo porque delineia importantes elementos da sociedade de transição para o comunismo. Moro, 2006.

\section{§ 1. Notas introdutórias}

Hoje em dia, mais frequentemente nos países ocidentais do que na sua dita periferia, falar-se em "maquinaria", ainda mais em "grande indústria", pode tanger a anacronismo. Não porque esta(s) tenha(m) deixado de existir ou de desempenhar um papel fundamental no cotidiano social, mas porque tende-se cada vez mais a desviar o olhar (quase exclusivamente) para os desenvolvimentos tecnológicos a nível digital, mais precisamente, para os elementos de consumo individual (apetrechos tais como telemóveis, computadores, etc., e aplicações atinentes), enfim, a "amar a cornucópia das novas inovações" (cf. WARSH, 2006: 147) ${ }^{1}$.

Por isso, não deixamos de assinalar que ao pretender recuperar a reflexão de Karl Marx (1818-1883), acerca do desenvolvimento tecnológico, ou de uma "teoria da maquinaria" (cf. SMITH, 2009: 113), estamos a fazê-lo, muito certamente, a contrapelo. De facto, ao contrário de um certo entendimento dominante, entende-se, e não é caso isolado, que esta reflexão não terá ficado refém do seu século (cf., a atual epígrafe, MORO, 2006: 109-110).

Mas ainda antes de se avançar para tal empreitada gostaríamos de gorar, desde já, algumas expetativas que se possam criar em torno do presente.

Em primeiro lugar, não pretendemos proceder a qualquer atualização da reflexão de Marx, tendo em conta, por exemplo, o que alguns autores têm chamado de Segunda Revolução Industrial: depois de uma primeira - que substituiu o trabalho braçal pelas máquinas -, encontramo-nos agora numa segunda - substituição do trabalho intelectual por outras máquinas e/ou outras tecnologias várias (cf., por exemplo, BRYNJOLFSSON; McAFEE, 2014; há quem já se refira a uma quarta Revolução). Contamos com o suporte da subsequente exposição para que o enquadramento dos desenvolvimentos hodiernos seja de certa maneira compreendido 2 .

Em segundo lugar, não contamos proceder a qualquer confronto com outras perspetivas que também refletiram acerca da tecnologia, como, por exemplo, a neo-

\footnotetext{
${ }^{1}$ É uma tendência que encontra raízes na chamada divisão internacional do trabalho e na maneira como é descentralizada dos centros ocidentais para outros lados do mundo a maior parte das grandes indústrias. $\mathrm{O}$ trabalho operário não desapareceu, apenas se deslocalizou e em alguns setores até se regista um aumento considerável (cf. MORO, 2006: 63-64).

2 Todavia, pode ser interessante passar uma vista de olhos no seguinte: SMITH, 2000, autor que ensaia uma crítica marxista à "nova economia", tomando em consideração a tecnologia.
}

ANTUNES, Paulo Fernando Rocha. Marx, maquinaria e grande indústria: o desenvolvimento tecnológico no Livro I de Das Kapital. Griot : Revista de Filosofia, Amargosa, Bahia, v.16, n.2, p.36-55, dezembro/2017. 
schumpeteriana ("economista evolucionista"). Desde logo se assinala que falta tanto a esta (apesar de lograr algumas coincidências com a reflexão de Marx), como à maior parte das restantes, algo de fundamental (e que nos vai guiar mais adiante): "esquecem-se" de pensar a relação entre a tecnologia e o capital(ismo), (cf. KATZ, 1996; SMITH, 2004) ${ }^{3}$.

Em terceiro lugar, nem vamos proceder a uma defesa da reflexão marxista face às suas críticas, no que diz respeito ao desenvolvimento tecnológico, sendo a principal destas a que a acusa de enfermar de um "determinismo tecnológico"; crítica, por sua vez, quase sempre alicerçada num determinado entendimento do papel das forças produtivas (Produktivkräfte) ${ }^{4}$. Não o faremos, pelo menos diretamente, porquanto estamos convictos de que em Marx não existe tal "determinismo" e de que a exposição subsequente o poderá deixar suficientemente esclarecido. (No entanto, reservamos para arremate um breve comentário.)

Enfim, também não vai ser possível no espaço disponibilizado abordar a generalidade das obras do autor alemão a propósito do nosso tema. Deste modo, teremos de nos circunscrever à sua principal obra - Das Kapital (1867) -, ao seu Livro I, mais precisamente, ao seu $13 .^{\circ}$ capítulo - "Maquinaria e grande indústria" (Maschinerie und große Industrie) - ${ }^{5}$, que se situa na $4 .{ }^{a}$ secção acerca da produção de mais-valia relativa (a ver já a seguir). Este texto acaba por corresponder à maturação do pensamento do autor acerca do desenvolvimento tecnológico, decorrida ao longo de uma década verdadeiramente fecunda ${ }^{6}$.

Certamente, muito mais haverá a dizer sobre o autor e o presente tema, mas por agora é isto que nos compete expor ${ }^{7}$.

\footnotetext{
${ }^{3}$ Como é dito, outros confrontos também poderiam ser estabelecidos e vão ser igualmente preteridos fica para exemplo daqueles que não se "esquecem" do papel do capital, pois o vão considerar essencial para o desenvolvimento tecnológico, a referência aos teóricos do "crescimento tecnológico endógeno ao capitalismo" (cf. SMITH, 2009).

${ }^{4}$ Para exemplo de alguns destes críticos, cf. SHAW, 1978: 53-82, autor que recorre, precisamente, à conceção marxista relacionada com as forças produtivas; DIÉGUEZ, 2005, embora este autor recorra à Miséria da Filosofia (1847), reconhece que há outros textos em que o autor alemão não é determinista; e, ADLER, 2007, autor que aponta o "determinismo tecnológico" a uma "leitura ortodoxa" de Marx; para a defesa do autor alemão, cf. ROPOHL, 1983: 95, autor que utiliza a teoria marxista de reificação (Verdinglichung) para criticar, precisamente, o "determinismo tecnológico"; BIMBER, 1990, autor que iliba Marx de pelo menos três tipos de "determinismo tecnológico"; e, KATZ, 1998, autor que considera tal acusação fruto de não se perceber o real "determinismo histórico-social", determinismo que, por sua vez, não negará o papel da "intencionalidade". Conquanto, o que significa "determinismo tecnológico" é ainda pouco consensual, pois têm sido atribuídas caraterísticas assaz diversas, e sido apontado a autores do mais heterogéneo matiz (cf. BIMBER, 1990: 333-334; DIÉGUEZ, 2005: 3).

${ }^{5}$ Para um resumo acessível do mesmo, reportando em alguns casos à atualidade, cf. MORO, 2006: 5571.

${ }^{6}$ Vejam-se as suas reflexões ao longo dos Grundrisse (1857-58), mas também nos Manuscritos de 18611863 (cf. 318-347), entre outras localizações mais dispersas ou distantes acerca do mesmo tema (cf. por exemplo, MARX, 1847; 1851).

${ }^{7}$ Para outros entendimentos, cf., por exemplo, AXELOS, 1961: 77-85, ainda que o objetivo do autor seja mais orientado para a reflexão acerca do caráter alienante e apresente algumas insuficiências quanto à dialética em Marx; DUSSEL, 1988, embora o objeto de estudo deste autor se concentre mais nos Manuscritos de 1861-63; WOOD, 1995: 108-145, autora que se concentra em criticar alguns marxistas; KATZ, 1997, autor que encontra o seu foco no confronto com diversas variantes do marxismo e pós-marxismo; e, FEENBERG, 2010, autor que vem trabalhando sistematicamente a
} 


\section{§ 2. Acumulação de capital e mais-valia}

Para uma mais exata compreensão do desenvolvimento da tecnologia a partir da reflexão de Marx, mais especificamente, para uma compreensão do papel da tecnologia em capitalismo é devido o esforço de se assinalar mesmo que grosso modo algumas caraterísticas do próprio modo de produção (Produktionsweise) capitalista.

Este modo de produção tem uma origem, ao contrário do que alguns pensadores, inclusive bastante cotados na praça pública, permitem compreender. Principalmente quando estes comentadores se arvoram em teorias que apontam o capital como alguma coisa comum a todos os tempos, como se representasse os meios, a possibilidade, de empreendimento humanos no geral (cf., por exemplo, ALCHIAN; ALLEN, 1964: 173).

Marx discorre abundantemente acerca da origem do capitalismo, em Das Kapital dedica-lhe o 24..$^{\circ}$ capítulo - "A chamada acumulação original" (Die sogenannte ursprüngliche Akkumulation) -, apontando diversos momentos que contribuíram para uma acumulação, ainda não propriamente capitalista, de capital. Aí, encontram-se a expropriação dos camponeses da terra, a legislação (sangrenta) contra os expropriados, a génese do rendeiro capitalista e do capitalista industrial (cf. 1867: 741-791).

Estes momentos correspondem a parte do processo europeu que permitiu o aparecimento das relações de produção capitalistas propriamente ditas. $O$ capital não é uma coisa, mas uma relação social. $O$ capital corresponde à relação entre os detentores dos meios de produção (Produktionsmittel, e dos instrumentos de produção em igual modo) e os trabalhadores assalariados. Aqui se revela o papel da propriedade privada no que diz respeito à divisão social em classes, na medida em que o acumulado é uma relação de poder por parte dos proprietários da produção.

Portanto, um dos fatores mais decisivos para a constituição do capitalismo foi a separação (expropriação) do trabalhador do seu instrumento de trabalho (Arbeitsinstrument), uma vez que este deixou de ter possibilidade de produzir a sua própria subsistência sem ter de empregar a sua força de trabalho (Arbeitskraft) nos meios de outrem ${ }^{8}$.

O trabalho assalariado (Lohnarbeit) é aqui o passo decisivo de afirmação de um novo sistema de produção ${ }^{9}$. É com a nova constituição de um dia de trabalho,

reflexão marxista sobre a tecnologia, sendo este só um exemplo (vejam-se as suas referências bibliográficas); entre muitos outros, pois a bibliografia é quilométrica.

8 «A chamada acumulação original nada é, portanto, senão o processo histórico de separação de produtor e meios de produção. Ela aparece como "original" porque forma a pré-história do capital e do modo de produção que lhe corresponde. A estrutura económica da sociedade capitalista proveio da estrutura económica da sociedade feudal. A dissolução desta libertou os elementos daquela.» - «Die sog ursprüngliche Akkumulation ist also nichts als der historische Scheidungsprozeß von Produzent und Produktionsmittel. Er erscheint als „ursprünglich”, weil er die Vorgeschichte des Kapitals und der ihm entsprechenden Produktionsweise bildet. Die ökonomische Struktur der kapitalistischen Gesellschaft ist hervorgegangen aus der ökonomischen Struktur der feudalen Gesellschaft. Die Auflösung dieser hat die Elemente jener freigesetzt.» (MARX, 1867: 742-743).

9 «As suas [do capital] condições históricas de existência não estão de modo algum dadas com a circulação das mercadorias e do dinheiro. Surge apenas onde o possuidor de meios de produção e de vida se depara no mercado com o operário livre como vendedor da sua força de trabalho, e [só] esta

ANTUNES, Paulo Fernando Rocha. Marx, maquinaria e grande indústria: o desenvolvimento tecnológico no Livro I de Das Kapital. Griot : Revista de Filosofia, Amargosa, Bahia, v.16, n.2, p.36-55, dezembro/2017. 
dividido em duas partes, que o capitalista encontra o substancial da sua vantagem. $O$ dia de trabalho divide-se em tempo de trabalho necessário (notwendige Arbeitszeit) - o que o trabalhador produz com vista à sua subsistência -, e sobretrabalho (Mehrarbeit) - o que o trabalhador trabalha a mais com vista ao embolso do proprietário dos meios de produção (cf. MARX, 1867: 231-232).

O que nos interessa reter, para já, é a questão da acumulação propriamente dita.

Marx considera a acumulação pré-capitalista, mas, mais precisamente, a capitalista, como a fagulha da concorrência (do mercado) capitalista (cf. 1867: 655). Visto que no mercado que o capitalismo desenvolve - isto é, que as novas relações sociais de produção propiciam -, a produção se distancia da satisfação das necessidades humanas e busca, antes, a produção em massa visando o mercado (e os seus consumidores no geral), visando também os seus concorrentes, privilegiando o mercado de consumo (cf. MARX, 1867: 335).

A acumulação de capital permite ao capitalista fazer face aos desafios que o mercado lhe coloca, desde a possibilidade de investir em mais trabalhadores (se tal for indispensável para a melhoria da quantidade produzida), de alargar a sua produção, de ditar as regras ou, pelo menos, os preços de mercado, e também determinar questões salariais com maior veemência.

É porque os concorrentes acumularam mais, ou perspetiva-se que o venham a fazer, que é preciso a cada capitalista (não interessa se isoladamente ou em associação) concorrer por mais capital. $O$ capital precisa de ser permanentemente autovalorizado - trata-se de um processo de autovalorização (Selbstverwertung, cf. MARX, 1867: 350) do capital que é investido

Falta ver, então, como se processa a acumulação (pós-originária) de capital. Este, depois da sua origem não volta mais (exceto em alguns casos particulares e quase sempre isolados) a acumular-se da mesma maneira, ou seja, não volta mais a acumular-se sem a forma laboral propriamente capitalista já desenvolvida - o trabalho assalariado. $\mathrm{O}$ capital é, agora, sempre correspondente a trabalho passado não pago (cf. MARX, 1867: 556), mesmo que na forma de juros, especulação, etc.

O capital é, assim, oriundo de sobretrabalho e este trabalho a mais corresponde à mais-valia (Mehrwert) ${ }^{10}$. A mais-valia, vantagem social do capitalista, é produzida no ato da produção, no momento em que o trabalhador produz algo em

condição histórica encerra [toda] uma história universal [Weltgeschichte]. O capital anuncia, pois, desde o início, uma época do processo social de produção.» - «Seine historischen Existenzbedingungen sind durchaus nicht da mit der Waren- und Geldzirkulation. Es entsteht nur, wo der Besitzer von Produktions- und Lebensmitteln den freien Arbeiter als Verkäufer seiner Arbeitskraft auf dem Markt vorfindet, und diese eine historische Bedingung umschließt eine Weltgeschichte. Das Kapital kündigt daher von vornherein eine Epoche des gesellschaftlichen Produktionsprozesses an.» (MARX, 1867: 184).

${ }^{10}$ «A este incremento [em relação ao valor adiantado] ou o excesso sobre o valor originário chamo eu [Marx] - mais-valia (surplus value). O valor originariamente adiantado não apenas se mantém, portanto, na circulação, mas nela altera a sua magnitude de valor, acrescenta uma mais-valia ou valoriza-se. E este movimento transforma-o em capital.» - «Dieses Inkrement oder den Überschuß über den ursprünglichen Wert nenne ich - Mehrwert (surplus value). Der ursprünglich vorgeschoßne Wert erhält sich daher nicht nur in der Zirkulation, sondern in ihr verändert er seine Wertgröße, setzt einen Mehrwert zu oder verwertet sich. Und diese Bewegung verwandelt ihn in Kapital.» (1867: 165).

ANTUNES, Paulo Fernando Rocha. Marx, maquinaria e grande indústria: o desenvolvimento tecnológico no Livro I de Das Kapital. Griot : Revista de Filosofia, Amargosa, Bahia, v.16, n.2, p.36-55, dezembro/2017. 40 
meios alheios (até pode ser cortar a barba numa barbearia, etc., o fundamental é servir para venda).

A mais-valia pode ser obtida de duas maneiras.

Por um lado, pela extensão do dia de trabalho, na medida em que o trabalhador tenha de trabalhar mais horas, pressupõe-se que produz mais, e, assim, deve produzir maior quantidade de mais-valia. A isto corresponde a mais-valia absoluta (absoluter Mehrwert, cf. MARX, 1867: 192 ss.), que mantém o trabalho necessário nos mesmos parâmetros, mas faz aumentar o sobretrabalho.

Por outro lado, a mais valia pode ser obtida de maneira a não estender o dia de trabalho, pode até diminuí-lo, mas aí terá de fazer aumentar o sobretrabalho na proporção em que diminui o tempo de trabalho necessário. A isto corresponde a mais-valia relativa (relativer Mehrwert, cf. MARX, 1867: 331 ss.), que exige uma revolução (mudança) nos meios, nos instrumentos, de produção, com vista a aumentar e melhorar a capacidade produtiva ${ }^{11}$.

Dada a possibilidade de se colocar o trabalhador a produzir em menos tempo o que é necessário para a sua subsistência, então, está dada a possibilidade de aumentar a mais-valia, logo, o capital. Contanto que se tenha em consideração que a mais-valia é produzida na hora da produção de algo, mas a sua realização (Realisierung) dá-se apenas no ato da troca, da transação, isto é, um produto que não encontre aceitação no mercado significa capital estagnado ou desperdiçado. O Capital é sempre investimento adiantado e depois mais-valia convertida.

É na possibilidade de aumentar e melhorar a produção (dadas determinadas condições de extração de mais-valia), com vista a uma maior autovalorização do capital, que soa a hora do desenvolvimento tecnológico em capitalismo (cf. MARX, 1867: 494, 495; SMITH, 2004: 224, 229) ${ }^{12}$.

\footnotetext{
11 «Isto [abaixamento do valor da força de trabalho], porém, é impossível sem uma elevação da força produtiva do trabalho. [...] [a força produtiva não pode aumentar] sem uma modificação nos seus [o exemplo é o de um sapateiro] meios de trabalho ou no seu método de trabalho ou em ambos simultaneamente. Teria, pois, de se dar uma revolução [Änderung] nas condições de produção do seu trabalho, i. é, no seu modo de produção, e, portanto, no próprio processo de trabalho. Por elevação da força produtiva do trabalho entendemos aqui, em geral, uma modificação no processo de trabalho através da qual o tempo de trabalho socialmente requerido para a produção de uma mercadoria é reduzido; um menor quantum de trabalho adquire, portanto, força para produzir um maior quantum de valor de uso.» - «Dies ist jedoch unmöglich ohne eine Erhöhung der Produktivkraft der Arbeit. Mit gegebnen Mitteln kann ein Schuster z. B. ein Paar Stiefel in einem Arbeitstag von 12 Stunden machen. Soll er in derselben Zeit zwei Paar Stiefel machen, so muß sich die Produktivkraft seiner Arbeit verdoppeln, und sie kann sich nicht verdoppeln ohne eine Änderung in seinen Arbeitsmitteln oder seiner Arbeitsmethode oder beiden zugleich. Es müß daher eine Revolution in den Produktionsbedingungen seiner Arbeit eintreten, d.h. in seiner Produktionsweise und daher im Arbeitsprozeß selbst. Unter Erhöhung der Produktivkraft der Arbeit verstehn wir hier überhaupt eine Verändrung im Arbeitsprozeß, wodurch die zur Produktion einer Ware gesellschaftlich erheischte Arbeitszeit verkürzt wird, ein kleinres Quantum Arbeit also die Kraft erwirbt, ein größres Quantum Gebrauchswert zu produzieren.» (sublinhados nossos, MARX, 1867: 333).

12 Em igual medida, será importante para uma maior compreensão do que aqui se encontra em causa a análise do papel do Estado, principalmente no que concerne às políticas relacionadas com o desenvolvimento tecnológico, mas também ao âmbito do poder da classe que as/o domina. Por exemplo, a "acumulação original" terá sido favorecida por medidas protecionistas (cf. MORO, 2006: 128).
}

ANTUNES, Paulo Fernando Rocha. Marx, maquinaria e grande indústria: o desenvolvimento tecnológico no Livro I de Das Kapital. Griot : Revista de Filosofia, Amargosa, Bahia, v.16, n.2, p.36-55, dezembro/2017. 


\section{§ 3. Desenvolvimento tecnológico em capitalismo}

Considerando a reflexão de Marx, a tecnologia serve o propósito, em capitalismo, de aumentar a produção (com vista a maior extração de mais-valia, à acumulação de capital) - diminuindo o tempo de trabalho necessário, aumentando o sobretrabalho -, da maneira como são introduzidas inovações a par da melhoria e do aceleramento das condições produtivas.

De troco, tal aplicação da tecnologia embaratece a mercadoria e o trabalhador para além de fazer face à concorrência ${ }^{13}$. Não obstante, a tecnologia em capitalismo serviu também outros propósitos com aqueles relacionados, nomeadamente, o de quebrar a resistência dos trabalhadores (cf. MARX, 1867: 424).

Ora, no final do período manufatureiro (europeu, mas em particular em Inglaterra) as unidades de produção capitalistas haviam atingido os seus limites. À medida que a expropriação sobre o trabalho disperso avançou e se criou um mercado de consumidores cada vez maior - uma vez que não podiam produzir a sua subsistência e terem de a comprar -, a demanda passou a exigir um ritmo maior de produção que a manufatura não podia comportar - visto que o trabalho manual padece das limitações físicas próprias do ser humano.

Este limite manufatureiro associou-se às condições que permitiam ao trabalhador formar coalizões, unir-se em favor das suas reivindicações, exigir a diminuição do dia de trabalho, por exemplo (o que "bloqueava" a mais-valia absoluta). Os trabalhadores tinham (algumas) condições de o fazer dado que o trabalho manual exigia uma certa habilidade (condição subjetiva do trabalho, segundo Marx) e o proprietário dos meios de produção não podia abdicar facilmente de um trabalhador experiente.

As novas condições de produção, proporcionadas pelo desenvolvimento da tecnologia produtiva, permitiram introduzir um fator produtivo objetivo, quer dizer, que não dependesse da habilidade dos trabalhadores. Passou a ser possível introduzir na linha de montagem pessoas pouco qualificadas, mas com capacidade suficiente para levar adiante o exigido. Passou a ser possível integrar mulheres e crianças nas fábricas, nivelando os salários por baixo, uma vez que aquelas se dispunham a receber menos do que os homens, por causa da sua falta de prática e condição social (cf. MARX, 1867: 416 ss.).

Por conseguinte, o desenvolvimento das condições de produção por parte do capitalista afirma-se, antes de tudo, por via da necessidade de autovalorização do capital, mas, como visto, tendo em linha de conta fazer face à concorrência e "quebrar a resistência" dos trabalhadores, ambos fatores que podem entravar aquela 14 .

Marx chegou a referir a aplicação da tecnologia em capitalismo como um "meio de guerra" (Kriegsmittel) dos capitalistas contra os trabalhadores, uma vez

13 Tenha-se em atenção que a tecnologia (a maquinaria) não cria valor por si só: por se investir genericamente nesta, ela realmente permite que o trabalho humano, única fonte de criação de valor, possa ser melhor adequado à extração de maior quantidade de mais-valia (cf. MARX, 1867: 408).

14 Mas também como necessidade de controlar socialmente a força da natureza, de a governar e apropriar-se dela por meio de obras da mão humana em grande escala, o que desempenhou o papel mais decisivo na história da indústria (cf. MARX, 1867: 536).

ANTUNES, Paulo Fernando Rocha. Marx, maquinaria e grande indústria: o desenvolvimento tecnológico no Livro I de Das Kapital. Griot : Revista de Filosofia, Amargosa, Bahia, v.16, n.2, p.36-55, dezembro/2017. 
que sempre que estes apareciam unidos em torno de alguma reivindicação, logo surgia um novo invento tecnológico para ocupar o seu lugar (cf. 1867: 459) ${ }^{15}$.

Atente-se a algumas das consequências que o desenvolvimento da maquinaria e da grande indústria comportou(a):

$O$ aumento da intensidade do trabalho. Os trabalhadores passaram a produzir muito mais em menor tempo do que antes, foram integrados como peças de uma máquina, o trabalho mecanizado acelerado passou a exigir menor habilidade pessoal, bem como as suas condições de saúde viram-se atacadas por via dos novos ritmos de trabalho e condições específicas da própria maquinaria (cf. MARX, 1867: 431 ss.).

A transformação da família. Com a integração da restante família no trabalho "social" as mulheres e as crianças passaram a apresentar-se de outra maneira - não tanto como propriedade do homem -, mas tal, naquelas condições, significou uma nova miserabilização, repare-se que o núcleo familiar viu os salários serem nivelados por baixo, o que teve como consequência a maior parte das famílias ganharem tanto (ou ainda menos) em conjunto do que o homem sozinho ganhava anteriormente (cf. MARX, 1867: 417).

$O$ recrudescimento do desemprego - ou melhor, como Marx lhe chamava, a criação e ampliação de um "exército industrial de reserva" (industrielle Reservearmee, cf. 1867: 657 ss.). As novas tecnologias não exigiam que se empregasse tantos trabalhadores como até ao auge do período manufatureiro. Aqui fora necessário empregar o máximo de trabalhadores que se pudesse, uma vez que a demanda o exigia. Mas com as novas tecnologias e a produzir tanto em menos tempo, foi possível substituir o trabalho braçal pela maquinaria. Este é um "exército" que quase se autorreproduz, pois os trabalhadores, sem possibilidade de produzir a sua própria subsistência, vêem-se na situação de tudo ter de fazer para poder estar empregados: os que estão empregados sujeitam-se a piores condições para manter o emprego e os que não estão, tenderão a aceitar ainda piores condições dos que estão empregados para poder voltar ao emprego.

$O$ aumento do capital constante (konstantes Kapital) ${ }^{16}$. Esta é mais uma das consequências do impulso imanente (immanenter Trieb) e tendência constante (beständige Tendenz) do capitalismo em inovar a sua força produtiva, as suas condições tecnológicas (cf. MARX, 1867: 338). Todavia, não logramos espaço suficiente para aprofundar esta questão: tal levaria a cotejar (com algum detalhe) parte das reflexões de Marx do seu Livro III, embora no Livro I, que nos serve de base para a presente exposição, se encontrem repercussões no âmbito da composição do capital que valeriam a pena estudar (cf. MARX, 1867: 640 ss.; MORO, 2006: 98), mas deixemo-lo para outra ocasião e mais à frente encerremos com um breve apontamento.

\footnotetext{
15 Marx vai caraterizar o desenvolvimento tecnológico sob as relações de produção capitalistas como uma das expressões de "despotismo do capital” (Despotie des Kapitals, cf. 1867: 674).

16 «Portanto, a parte do capital que se converte em meios de produção, i. é, em matéria-prima, matérias auxiliares e meios de trabalho, não modifica a sua magnitude de valor [Wertgröße] no processo de produção. Chamo-lhe, por isso, parte constante do capital, ou mais resumidamente: capital constante.» - «Der Teil des Kapitals also, der sich in Produktionsmittel, d. h. in Rohmaterial, Hilfsstoffe und Arbeitsmittel umsetzt, verändert seine Wertgröße nicht im Produktionsprozeß. Ich nenne ihn daher konstanten Kapitalteil, oder kürzer: konstantes Kapital.» (MARX, 1867: 223).
}

ANTUNES, Paulo Fernando Rocha. Marx, maquinaria e grande indústria: o desenvolvimento tecnológico no Livro I de Das Kapital. Griot : Revista de Filosofia, Amargosa, Bahia, v.16, n.2, p.36-55, dezembro/2017. 
Tendo em vista todas estas consequências ${ }^{17}$, não é por acaso que Marx vai considerar a passagem de uma subsunção formal (formelle Subsumtion) do trabalhador em capitalismo para uma subsunção real (reelle Subsumtion).

A primeira, em rigor, concerne ao período manufatureiro, porque os trabalhadores já se encontravam subsumidos sob a forma de trabalho assalariado, mas alguma coisa da sua parte ainda era necessária (por exemplo, a habilidade) ${ }^{18}$.

A segunda, em rigor, concerne à introdução da maquinaria e da grande indústria, visto que o trabalhador foi socialmente reduzido (subsumido), no fundamental, a uma "simples" peça das máquinas e passou a ter muito menos capacidade de se libertar da esfera do capital. Em rigor, pode-se dizer que se mantém a forma, mas adensa-se o conteúdo (cf. MARX, 1867: 533; DUSSEL, 1988: 41-42, para uma catalogação de 8 aspetos do modo como o capital utiliza a máquina para subjugar o trabalho) ${ }^{19}$.

Passa-se, assim, do aumento do dia de trabalho para a transformação completa das condições de trabalho.

$\mathrm{Na}$ verdade, serve de exemplo o facto de a luta pela diminuição do dia de trabalho (contra a mais-valia absoluta) ter sido esboroada: dada a degradação do estado dos trabalhadores perante o proprietário dos meios de produção, logo tiveram de ver o capitalista aumentar a intensidade da produção, mas também o dia de

$17 \mathrm{O}$ que não quer dizer que os capitalistas, agindo cada um por si, pelos seus próprios interesses, estivessem completamente conscientes da generalidade das consequências de suas práticas, quer num primeiro momento, individual, quer num segundo, social. Pode-se encontrar parte deste processo resumido quase duas décadas antes de Das Kapital, dando igual relevo à divisão do trabalho (Teilung der Arbeit), no fundo: «Um capitalista só pode pôr outro em fuga e conquistar-lhe o capital vendendo mais barato. Para poder vender mais barato sem ir à ruína tem de produzir mais barato, isto é, aumentar tanto quanto possível a força produtiva do trabalho [Produktionskraft der Arbeit]. Mas a força produtiva do trabalho é sobretudo aumentada por meio de uma maior divisão do trabalho, por meio de uma introdução generalizada e de um aperfeiçoamento constante da maquinaria. Quanto maior é o exército de operários entre os quais o trabalho se divide, quanto mais gigantesca a escala em que se introduz a maquinaria, tanto mais diminuem proporcionalmente os custos de produção, tanto mais rico se torna o trabalho. Nasce daqui uma competição generalizada entre os capitalistas para aumentarem a divisão do trabalho e a maquinaria e as explorarem à maior escala possível.» - "Der eine Kapitalist kann den andern nur aus dem Felde schlagen und sein Kapital erobern, indem er wohlfeiler verkauft. Um wohlfeiler verkaufen zu können, ohne sich zu ruinieren, muß er wohlfeiler produzieren, d.h. die Produktionskraft der Arbeit soviel wie möglich steigern. Die Produktionskraft der Arbeit wird aber vor allem gesteigert durch eine größere Teilung der Arbeit, durch eine allseitigere Einführung und beständige Verbesserung in der Maschinerie. Je größer die Arbeiterarmee ist, unter welche die Arbeit geteilt, je riesenhafter die Stufenleiter ist, auf welcher die Maschinerie eingeführt wird, um so mehr nehmen verhältnismäßig die Produktionskosten ab, um so fruchtbarer wird die Arbeit. Es entsteht daher ein allseitiger Wetteifer unter den Kapitalisten, die Teilung der Arbeit und die Maschinerie zu vermehren und sie auf möglichst großer Stufenleiter auszubeuten.» (MARX, 1849: 417).

18 Para um aprofundamento do papel da cooperação (Kooperation), passagem do trabalho isolado para trabalho social, em relação à subsunção, cf. DUSSEL, 1988: 30-31.

19 A chamada "verdade tecnológica" (technologische Wahrheit) é expressão da mais violenta confrontação, nomeadamente, da subsunção real do trabalhador perante o capital, numa relação mediada pela maquinaria, tecnologia e ciência (cf. DUSSEL, 1988: 178-179). O que trata de parte da satisfação da compulsão do capital por mais-valia; a incompreensão deste fenómeno poderá ser chamada de "ingenuidade tecnológica" (technological naïveté, cf. MURRAY, 2004: 282). Para uma consideração de outros tipos de subsunção ("híbrida" e "ideal") nos escritos de Marx, em Das Kapital ou nos Manuscritos de 1861-63, cf. MURRAY, 2004: 263 ss.

ANTUNES, Paulo Fernando Rocha. Marx, maquinaria e grande indústria: o desenvolvimento tecnológico no Livro I de Das Kapital. Griot : Revista de Filosofia, Amargosa, Bahia, v.16, n.2, p.36-55, dezembro/2017. 
trabalho - mais-valia absoluta e relativa combinam-se com vista à maior autovalorização de capital.

O capitalismo atinge, deste modo, a sua maturação. A Revolução Industrial não inventa o capitalismo, este serve-se daquela, pois é produto das necessidades de expansão e desenvolvimento capitalistas (cf. MARX, 1867: 395-396) ${ }^{20}$. A tecnologia serviu este propósito e serve enquanto garantir vantagem na luta de vida ou de morte da concorrência - se o capitalista não for a jogo pela autovalorização do seu capital, pode ser deixado de fora do mercado ${ }^{21}$. Segundo o autor, «Se a força motriz parte agora do homem ou mesmo por sua vez de uma máquina, isso em nada altera a essência da coisa.» $\left(1867: 394{ }^{22}\right)^{23}$.

\section{§ 4. Das contradições à superação do modo de produção em causa}

Contudo, a história não acabou(a) aí, quer dizer, não acaba com a subsunção total da vida humana, com o domínio do capital. Todo este processo aqui exposto acarreta contradições (insanáveis) do próprio sistema capitalista. É por isso que se insistiu em destacar o âmbito de uma aplicação rigorosamente capitalista da tecnologia, e não genericamente ou a par de outro caso particular ${ }^{24}$. Vejamos algumas dessas contradições.

${ }^{20}$ De acordo com Marx, o capital apodera-se, igualmente, da ciência, que até então não estava tão diretamente ligada aos processos produtivos: «A ciência não custa em geral "nada" ao capitalista, o que não o impede, de modo algum, de a explorar. A ciência "alheia" é incorporada ao capital tal como o trabalho alheio. Apropriação "capitalista" e apropriação "pessoal", seja de ciência seja de riqueza material, são porém inteiramente coisas díspares.» - «Die Wissenschaft kostet dem Kapitalisten überhaupt „nichts", was ihn durchaus nicht hindert, sie zu exploitieren. Die „fremde" Wissenschaft wird dem Kapital einverleibt wie fremde Arbeit. "Kapitalistische" Aneignung und „persönliche" Aneignung, sei es von Wissenschaft, sei es von materiellem Reichtum, sind aber ganz und gar disparate Dinge.» (1867: 407-408 n.). Uma das consequências do desenvolvimento tecnológico em capitalismo foi a captura da ciência pelas suas relações de produção, e o concebimento de uma "ciência totalmente moderna da tecnologia", unindo o disperso, conquanto tenha-se também em conta o carácter revolucionário desta base técnica face ao que havia dantes (cf. MARX, 1867: 510).

${ }^{21}$ A tecnologia é desenvolvida apenas enquanto puder garantir vantagem ao capitalista, pois este não está disposto a investir nela se não conseguir garantir lucros em relação aos trabalhadores que possa vir a dispensar, adverte Marx (cf. 1867: 415-416). Se assim é, fica claro que o modo de produção capitalista não é propriamente igual a tecnologia, ao invés, serve-se desta dadas as condições que lhe possam ser propícias. Não pode cair em olvido que o revolucionamento de uma maneira de produzir em determinada esfera da indústria condiciona o seu revolucionamento noutra, o que quer dizer que a cada avanço pode haver quem o queira impedir ou que existe uma tendência para nivelar conforme a concorrência vai aproximando as partes envolvidas (cf. MARX, 1867: 404). As condições dos trabalhadores, mas também as dos concorrentes, estão todas ligadas.

${ }^{22} « \mathrm{Ob}$ die Triebkraft nun vom Menschen ausgeht oder selbst wieder von einer Maschine, ändert am Wesen der Sache nichts.»

${ }^{23}$ O filme Modern Times (1936) ilustra-o com especial sagacidade - o novo tipo de trabalho sob as relações de produção capitalistas. Não obstante, para uma outra perspetiva acerca da relação de Marx com este filme, cf. WARTENBERG, 2007: 32-54 (apesar de algumas particularidades inerentes a um pensador da sua área), autor que confronta o clássico do cinema com os textos de juventude do alemão e foca mais na teoria da alienação e da exploração do trabalhador.

24 «Não é a máquina, nem qualquer compulsão tecnológica [technological compulsion], que inevitavelmente transforma os trabalhadores, e homens e mulheres em geral, em apêndices e escravos de monstruosos equipamentos. É o princípio capitalista de maximização do lucro [capitalist principle of profit maximization] por parte das empresas individuais que desencadeia essa terrível tendência.» -

ANTUNES, Paulo Fernando Rocha. Marx, maquinaria e grande indústria: o desenvolvimento tecnológico no Livro I de Das Kapital. Griot : Revista de Filosofia, Amargosa, Bahia, v.16, n.2, p.36-55, dezembro/2017. 
Comecemos pela que é, porventura, a mais "intuitiva" - a possibilidade de libertação laboral humana que a tecnologia parece proporcionar.

A introdução de novas tecnologias permite diminuir o tempo de trabalho necessário, como vimos, o que permite, por consequência, diminuir o tempo de trabalho total, visto que deixa de ser preciso trabalhar tanto como anteriormente para produzir o que é necessário. Mas nas condições de produção capitalista a introdução de novas invenções serve frequentemente para o contrário, serve para uma maior subjugação do trabalho ${ }^{25}$.

Se há alturas em que o trabalho se consegue libertar um pouco mais, mantendo-se as relações capitalistas, de acordo com o autor, isso terá que ver com a luta de classes ${ }^{26}$, porquanto não é inocente ou inócuo que, numa sociedade dividida entre proprietários dos meios de produção e expropriados destes, se reivindique por melhores condições de vida (ou, quando se vai mais longe do que isso, se lute para transformar desde a base a realidade social que se encontra dada), (cf., por exemplo, 1867: 249-250; ENGELS, 1883: 4).

«It is not the machine, nor any technological compulsion, which inevitably transforms workers and men and women in general into appendices and slaves of monstrous equipment. It is the capitalist principle of profit maximization by individual firms which unleashes this terrifying trend.» (MANDEL, 1990: 65).

25 Aqui podemos encontrar o verdadeiro "paradoxo tecnológico", ou "paradoxo económico" (ökonomische Paradoxon) como assevera o autor: «Se, portanto, o emprego [ou aplicação] capitalista da maquinaria [kapitalistische Anwendung der Maschinerie] cria, por um lado, novos motivos poderosos para o prolongamento desmedido do dia de trabalho - e revoluciona tanto o modo de trabalho como o carácter do corpo social de trabalho de uma espécie que quebra a resistência contra esta tendência -, por outro lado produz, em parte por contratação pelo capital de camadas da classe operária antes inacessíveis, em parte pelo licenciamento dos operários suplantados pelas máquinas, uma população operária excedente que tem de deixar que a lei lhe seja ditada pelo capital. Daí o notável fenómeno na história da indústria moderna de a máquina dar cabo de todas as barreiras éticas e naturais do dia de trabalho. Daí o paradoxo económico de o mais poderoso meio de redução do tempo de trabalho se converter no meio mais infalivel de transformar todo o tempo de vida do operário e da sua família em tempo de trabalho disponível para a valorização do capital.» - «Wenn also die kapitalistische Anwendung der Maschinerie einerseits neue mächtige Motive zur maßlosen Verlängrung des Arbeitstags schafft und die Arbeitsweise selbst wie den Charakter des gesellschaftlichen Arbeitskörpers in einer Art umwälzt, die den Widerstand gegen diese Tendenz bricht, produziert sie andrerseits, teils durch Einstellung dem Kapital früher unzugänglicher Schichten der Arbeiterklasse, teils durch Freisetzung der von der Maschine verdrängten Arbeiter, eine überflüssige Arbeiterpopulation, die sich das Gesetz vom Kapital diktieren lassen muß. Daher das merkwürdige Phänomen in der Geschichte der modernen Industrie, daß die Maschine alle sittlichen und natürlichen Schranken des Arbeitstags über den Haufen wirft. Daher das ökonomische Paradoxon, daß das gewaltigste Mittel zur Verkürzung der Arbeitszeit in das unfehlbarste Mittel umschlägt, alle Lebenszeit des Arbeiters und seiner Familie in disponible Arbeitszeit für die Verwertung des Kapitals zu verwandeln.» (sublinhados nossos, 1867: 430).

26 «Uns dizem que [a luta de classes] já acabou. Outros asseguram que nunca existiu. Outros ainda vão resmungando o murmúrio de que não é mais "pertinente", de que não é "relevante", ou tão-só "de bom gosto", mencioná-la e tê-la em consideração. E entretanto - escancarada, amortecida, mascarada, ou objeto de mistificações múltiplas - ela continua a irromper pela nossa atualidade.» (BARATA-MOURA, 2016: 213). Mas também é possível encontrar algumas confissões da parte de alguns capitalistas afamados, por exemplo: “"Há guerra de classes, tudo bem", disse [Warren] Buffett [1930-], “mas é a minha classe, a classe rica, que faz a guerra e estamos a ganhar".» - «"There's class warfare, all right," Mr. Buffett said, "but it's my class, the rich class, that's making war, and we're winning."» (STEIN, 2006, o mesmo, porventura, já não se pode dizer do autor do artigo).

ANTUNES, Paulo Fernando Rocha. Marx, maquinaria e grande indústria: o desenvolvimento tecnológico no Livro I de Das Kapital. Griot : Revista de Filosofia, Amargosa, Bahia, v.16, n.2, p.36-55, dezembro/2017. 
Depois, e parece escapar à maior parte dos apologistas do sistema em causa, que o chamado exército industrial de reserva - e o constante aumento deste, principalmente se não houver picos de produção -, elimina parte (quando não quase toda) da possibilidade de realização de mais-valia. Ora, com o crescimento do número de desempregados torna-se evidente a baixa do consumo ${ }^{27}$. $O$ capitalismo deve continuar a produzir (em busca de autovalorização), mas não tem quem compre o que é produzido. As crises de sobreprodução (Überproduktion), a necessidade de expansão dos mercados, encontram, de modo genérico, a sua explicação (cf., por exemplo, MARX, 1867: 476).

O capitalismo parece desenvolver-se (ou desenvolve-se mesmo) autofagicamente: os capitalistas que estão em direta concorrência uns com os outros vêem-se obrigados a investir (o caso acima referido do capital constante e encerra-se aqui o apontamento) para fazer face às exigências do mercado, mas esse investimento pode ser detido pelo investimento de outros, a sua taxa de lucro pode diminuir e, por consequência, sucumbir (esta é uma das consequências da necessidade do aumento do capital constante e da diminuição, ou desaparecimento, da sua autovalorização).

Na verdade, o capitalismo - que se apresenta como um modo de produção imensamente dependente do que a tecnologia lhe pode proporcionar, tendendo a superdesenvolvê-la - acaba por se tornar, inversamente, num bloqueador do próprio desenvolvimento tecnológico.

O capitalismo bloqueia o desenvolvimento da tecnologia porque se serve no essencial daquela que for eminentemente lucrativa, mesmo que a menos lucrativa possa trazer avanços significativos para a humanidade, pois se uma tecnologia não for rentável, sai de cena, ou nem chega a entrar ${ }^{28}$. Dado o espaço de concorrência

${ }^{27}$ «Se a classe inteira dos operários assalariados fosse destruída pela maquinaria, que horror para o capital, o qual sem trabalho assalariado deixa de ser capital?» - «Wenn die ganze Klasse der Lohnarbeiter durch die Maschinerie vernichtet würde, wie schrecklich für das Kapital, das ohne Lohnarbeit aufhört, Kapital zu sein?» (MARX, 1849: 421). Não é por acaso que pululam por aí os defensores de um Rendimento Básico Incondicional (RBI, ou rendimento básico universal, RBU), procurando defender a todo o custo o sistema de relações capitalistas de produção, uma vez que acabam por justificar o seu funcionamento, desde o crescente desemprego à sobreprodução (nos moldes que ditam o atual desenvolvimento tecnológico), etc., procurando salvaguardar a possibilidade de consumo, julgando poder assegurar às massas miserabilizadas condições para o continuar a fazer. "Apenas" ocultam a legitimação que o dito "rendimento básico" oferece à destruição do emprego, dos serviços sociais, entre outras coisas, bem como exortam a uma espécie de compensação pela existência da propriedade dos meios de produção (cf., por exemplo, BOOTH, 2017). Friedrich Engels (1820-1895) questiona ironicamente, a propósito das crises do capitalismo: «O tão suspirado período de prosperidade não virá; todas as vezes que parecemos sentir os sintomas que o anunciam, de novo eles se desvanecem no ar. Entretanto, cada novo Inverno volta a colocar a grande questão: "Que fazer com os desempregados?"» - «Die ersehnte Periode der Prosperität will nicht kommen; sooft wir die sie ankündigenden Symptome zu erblicken glauben, sooft verschwinden sie wieder in der Luft. Inzwischen stellt jeder folgende Winter erneut die Frage: „Was tun mit den Arbeitslosen?"» (1886: 40). A propósito, a crítica que Marx disfere ao conhecido Programa de Gotha acaba por visar tentativas à sua época semelhantes às que trazem para cima da mesa algo como o referido "rendimento" (cf. 1875).

${ }^{28} \mathrm{O}$ avião supersónico Concorde pode servir de exemplo de um avanço tecnológico que saiu de cena, devido aos seus elevados custos, e alguns combustíveis não (ou menos) poluentes como exemplo de avanços que nem chegaram a entrar em cena, por não garantirem imediata rentabilidade ou por baixarem a existente. A técnica dominante que vem a determinar os custos normais de produção não é necessariamente a mais avançada; a técnica socialmente necessária não é uma ideia da tecnologia,

ANTUNES, Paulo Fernando Rocha. Marx, maquinaria e grande indústria: o desenvolvimento tecnológico no Livro I de Das Kapital. Griot : Revista de Filosofia, Amargosa, Bahia, v.16, n.2, p.36-55, dezembro/2017. 
entre os capitalistas, as patentes são compradas, às vezes "metidas na gaveta" só para impedir um concorrente de despontar; encarecidas, tornando-se de difícil utilização pela generalidade dos cientistas; destruídas; etc. (cf. SMITH, 2004: 232 ss.).

Acima de tudo, o desenvolvimento da tecnologia, subjugado pelas relações sociais de produção capitalistas, obstaculiza a emancipação humana ${ }^{29}$. Contanto que não se compare face a outros modos de produção menos desenvolvidos como, por exemplo, o feudal. Em capitalismo só é possível diminuir-se o tempo de trabalho necessário, através do incremento tecnológico, por causa da sua compulsão por sobretrabalho, e não porque se pretenda diminuir efetivamente o dia de trabalho para os trabalhadores ou aumentar algum "fundo social".

A possível coincidência do tempo de trabalho necessário com o tempo de trabalho total (ou quase total) não é possível em capitalismo, se tal fosse possível já não seria capitalismo (cf. MARX, 1867: 552). Veja-se, se o capitalismo está dependente da acumulação de trabalho alheio não pago (e o que daí consiga derivar, entre prebendas, especulação, juros, etc.), então, não pode fazer coincidir as vantagens tecnológicas com a melhoria da qualidade de vida dos trabalhadores. Exceto se a luta de classes, ainda dentro do modo de produção em causa, permitir que haja avanços em favor da classe trabalhadora, de outra maneira tal não deixará de ser uma ilusão ${ }^{30}$. O capitalismo não pode existir sem sobretrabalho, o desaparecimento deste corresponderia a uma sociedade em transição, portanto, do capitalismo para o socialismo (cf. MORO, 2006: 81).

Não é por acaso que a primeira vez que Marx fala, em Das Kapital, na possibilidade de superação do modo de produção capitalista - em elementos de formação de uma nova sociedade -, seja aquando das suas reflexões acerca da

mas económica; daí que Marx alerte para uma conceção fácil de tecnologia (cf. EATWELL, 1990). Atente-se ainda à seguinte passagem: «De facto, o [jornal] The Economist, longe de ser uma publicação radical, argumentou recentemente que o regime de direitos de propriedade intelectual atualmente dificulta profundamente a inovação.» - «In fact, The Economist, a far from radical publication, has recently argued that the intellectual property rights regime now profoundly hampers innovation (Economist, 2002).» (SMITH, 2004: 234).

29 Para uma reflexão acerca dos malefícios para o desenvolvimento tecnológico, com ênfase na informação, que uma sociedade dividida em classes representa, cf. PERELMAN, 1998: 32-35, embora o autor não se afaste o suficiente de um certo "voluntarismo" e "educativismo".

30 «John Stuart Mill [1806-1873] nos seus Princípios de Economia Política [Principles of Political Economy, 1848] diz: “É questionável se todas as invenções mecânicas já feitas aliviaram a labuta diária de algum ser humano." - Marx comenta - Esse também não é, de modo algum, o objetivo da maquinaria empregue de modo capitalista. Tal como qualquer outro desenvolvimento da força produtiva do trabalho, ela há de embaratecer mercadorias e encurtar a parte do dia de trabalho de que o operário precisa para si mesmo, para prolongar aquela outra parte do seu dia de trabalho que ele dá gratuitamente ao capitalista. Ela é meio para a produção de mais-valia.» - «John Stuart Mill sagt in seinen "Prinzipien der politischen Ökonomie”: „Es ist fraglich, ob alle bisher gemachten mechanischen Erfindungen die Tagesmühe irgendeines menschlichen Wesens erleichtert haben." Solches ist jedoch auch keineswegs der Zweck der kapitalistisch verwandten Maschinerie. Gleich jeder andren Entwicklung der Produktivkraft der Arbeit soll sie Waren verwohlfeilern und den Teil des Arbeitstags, den der Arbeiter für sich selbst braucht, verkürzen, um den andren Teil seines Arbeitstags, den er dem Kapitalisten umsonst gibt, zu verlängern. Sie ist Mittel zur Produktion von Mehrwert.» (1867: 391).

ANTUNES, Paulo Fernando Rocha. Marx, maquinaria e grande indústria: o desenvolvimento tecnológico no Livro I de Das Kapital. Griot : Revista de Filosofia, Amargosa, Bahia, v.16, n.2, p.36-55, dezembro/2017. 
maquinaria e da grande indústria (cf. 1867: 526) 31. Este desenvolvimento tecnológico, apesar de aparecer "em invólucro capitalista" (in kapitalistischen Hülle), comporta em si possibilidades materiais de superação social até aí não existentes ${ }^{32}$. Assim sendo, comporta a possibilidade de se poder produzir em melhores e maiores condições a subsistência humana ${ }^{33}$.

Enfim, de acordo com o autor alemão, a tecnologia não está condenada a ser subjugada pelo capital. Ademais, a subsunção (real, com base na maquinaria ou tecnologia no geral) traz para a cena a generalização do assalariamento, isto é, o aumento dos trabalhadores assalariados, expropriados dos meios de produção, por um lado, e a diminuição dos detentores da produção, os expropriadores, por outro (cf., por exemplo, MORO, 2006: 67, 109) ${ }^{34}$. E no aumento desta clivagem social materializa-se o agudizar da luta de classes e a tomada de consciência do que está em causa e a possibilidade da sua superação ${ }^{35}$.

\section{§ 5. Arremate}

Em nosso entendimento, a reflexão de Marx aqui recuperada, acerca do desenvolvimento tecnológico, quase que poderia ser resumida no seguinte: é como as relações sociais (não esquecer as relações de propriedade, Eigentumsverhältnisse) se organizam, se desenvolvem historicamente, que vem a ser determinada a aplicação que se faz da tecnologia (não confundir com uma suposta "neutralidade tecnológica", a ver adiante) ${ }^{36}$.

31 O âmbito da aplicação da tecnologia, da maquinaria, na sociedade comunista é maior do que na

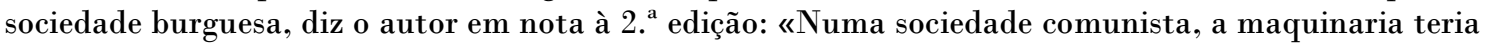
portanto todo um outro espaço de ação do que na sociedade burguesa.» - «In einer kommunistischen Gesellschaft hätte daher die Maschinerie einen ganz andren Spielraum als in der bürgerlichen Gesellschaft.» (1867: 414 n.; cf. MOHUN, 1983b: 331).

32 Daí que todos aqueles que procuraram projetar sociedades futuras libertas das amarras do vigente, caíram a maior parte das vezes em utopismo, mais propriamente em "socialismo utópico", dado que não atenderam às condições reais de superação da sociedade em causa (cf. ENGELS, 1880).

33 Para a compreensão, no seguimento da conceção materialista da história, da reprodução do viver humano, cf., por exemplo, MARX-ENGELS, 1845: 28; MARX, 1867: 185, 591 ss.).

${ }^{34}$ Cf., por exemplo, o relatório da Oxfam - Wealth: Having It All and Wanting More (2016) - que denuncia o facto de o $1 \%$ dos mais ricos do mundo deterem tanta riqueza como os $50 \%$ mais pobres.

35 Todavia, não se pode deixar de ter em conta o desenvolvimento "ziguezagueante" da própria história, para usar uma expressão de Engels, o que nem sempre bate certo com a "lógica" do nosso entendimento (cf. 1859: 475), bem como os desenvolvimentos sociais-económicos à escala global, visto que o sistema capitalista mundializou-se e as nações se influenciam mutuamente (cf. MARX, 1867: 790-791). Por não aparecer como decisiva para a presente exposição, deixou por se abordar a contradição que diz respeito ao âmbito da família, dado que a subjugação dos seus membros ao capital significa também libertação de parte deles do jugo paternal até aí vigente, com as devidas consequências que isso significa para a sociedade, igualmente dissecadas por Marx (cf. 1867: 514).

${ }^{36}$ Inclusive alguns cientistas do MIT, que tendem a entender a tecnologia como fonte de riqueza, advertem: «A tecnologia cria possibilidades e potencial, mas no final, o futuro que obtemos dependerá das escolhas que fizermos. Podemos colher uma recompensa e liberdade sem precedentes, ou o maior desastre que a humanidade já viu. [...] Na segunda era da máquina [second machine age], precisamos pensar muito mais profundamente sobre o que realmente queremos e o que valorizamos, tanto como indivíduos, como em sociedade. A nossa geração herdou mais oportunidades de transformar o mundo do que qualquer outra. Isso é motivo de otimismo, mas somente se estivermos conscientes das nossas escolhas. A tecnologia não é o destino. Nós moldamos o nosso destino.» - «Technology creates 
Atente-se ainda que na crítica que o autor alemão faz, não se encontra qualquer tendência neoludita - de apelo à destruição da maquinaria, por via dos constrangimentos que denuncia -, ou qualquer tendência romântica pré-tecnológica - de apelo a um regresso ao passado -; mas também não se encontra o reverso deste romantismo, digamos assim, um romantismo de outro tipo, isto é, o de um deslumbramento face às potenciais e efetivas conquistas tecnológicas e, desse modo, um depósito acrítico de "fé tecnologista" (cf. MANDEL, 1990: 37-38).

A perspetiva do autor está, por seu turno, assente em possibilidades materiais do próprio desenvolvimento tecnológico em capitalismo (quer nas suas potencialidades, quer nos seus limites). A maneira como a tecnologia pode servir a emancipação humana encontra-se diretamente ligada à produção social e à transformação da propriedade em causa.

É por isso que a reflexão na esteira de Marx não pode deixar de ter em conta o processo histórico, para o efeito: como se desenvolveu em primeiro momento o capitalismo, como se expandiu, as novas caraterísticas que foi assumindo (ainda que mantenha a fundamental sempre presente - a propriedade privada dos meios de produção e o trabalho assalariado), e os seus limites, tal como aconteceu com outros modos de produção, ou seja, com outras relações sociais de produção.

A partir da perspetiva de Marx pode-se compreender, mais apuradamente, o que várias teorias disseminadas pretendem significar - tanto as que apresentam a tecnologia como "a parteira das maiores catástrofes que a humanidade irá enfrentar" (as distopias, tecnológicas para o caso) ou as que a apresentam como "a maior das salvações" que há de acudir à humanidade, dadas as "maravilhas" da tecnologia respetivamente (as utopias tecnológicas), (cf. DIÉGUEZ, 2005: 9-10). Quer num caso como noutro não fazem mais do que projetar acrítica e a-historicamente para um futuro distante, ou às vezes nem tão distante assim, as "deformações" ou os "encantos" da sociedade face ao desenvolvimento tecnológico hodierno ${ }^{37}$.

possibilities and potential, but ultimately, the future we get will depend on the choices we make. We can reap unprecedented bounty and freedom, or greater disaster than humanity has ever seen before. [...] In the second machine age, we need to think much more deeply about what it is we really want and what we value, both as individuals and as a society. Our generation has inherited more opportunities to transform the world than any other. That's a cause for optimism, but only if we're mindful of our choices. Technology is not destiny. We shape our destiny.» (BRYNJOLFSSON; McAFEE, 2014: 186). Desde que se tenha o seguinte em atenção: «Os homens fazem a sua própria história, mas não a fazem segundo a sua livre vontade, em circunstâncias voluntariamente escolhidas, mas nas circunstâncias imediatamente encontradas, dadas e transmitidas.» - «Die Menschen machen ihre eigene Geschichte, aber sie machen sie nicht aus freien Stücken, nicht unter selbstgewählten, sondern unter unmittelbar vorgefundenen, gegebenen und überlieferten Umständen.» (MARX, 1852: $115)$.

37 Quando, de facto, a tecnologia é produto, contingente em relação à organização social precedente, e não a que cria, como determinante; por exemplo, a tecnologia tem valor de uso (cf. YOUNG, 1983: 535; BIMBER, 1990: 345). E vale, talvez, recuperar a epígrafe retirada de uma nota de rodapé de Das Kapital, com vista a destacar a importância dada a uma reflexão que tenha em consideração o desenvolvimento histórico, neste caso particular, da tecnologia, bem como o processo social. Agora no original: «Eine kritische Geschichte der Technologie würde überhaupt nachweisen, wie wenig irgendeine Erfindung des 18. Jahrhunderts einem einzelnen Individuum gehört. Bisher existiert kein solches Werk.» (1867: 392 n). A utilização desta passagem aqui não visou mais do que o referido supra, não se entende que entretanto não se tenha escrito alguma história (crítica) da tecnologia.

ANTUNES, Paulo Fernando Rocha. Marx, maquinaria e grande indústria: o desenvolvimento tecnológico no Livro I de Das Kapital. Griot : Revista de Filosofia, Amargosa, Bahia, v.16, n.2, p.36-55, dezembro/2017. 
Aqui sim, porventura se encontra o lugar apropriado para um "determinismo tecnológico" - nas teorias que persistem em ver no desenvolvimento tecnológico um desenvolvimento autónomo face ao tipo de relações sociais vigentes ou, indo ainda mais longe, um desenvolvimento absolutamente determinante ${ }^{38}$. Trata-se de uma análise parcial, à superfície, uma vez que tem pouco mais do que as possibilidades tecnológicas em real consideração ${ }^{39}$. $\mathrm{O}$ que pressupõe de alguma maneira uma certa "neutralidade" da tecnologia, ou seja, esta segue um curso inevitável, mas pode ser usada tanto para o "bem" como para o "mal".

Porém, não é desta maneira que o desenvolvimento da tecnologia se processa. O tipo de relações sociais que a desenvolvem determinam maioritariamente quais os avanços e objetivos a alcançar. Por isso, a transformação do modo de produção não dita apenas a nova aplicação da tecnologia, também ditará a nova tecnologia e a reformulação, em larga medida, da existente (cf. MOHUN. 1983a: 300) ${ }^{40}$.

Serve aqui recordar a teoria do "feiticismo" de Marx, igualmente exposta no Livro I d'O Capital (cf. 85 ss.), em que o autor faz a crítica à relação coisal (reificação) que as relações sociais adquirem - desde a sua "forma" mercadoria, dinheiro, inclusive tecnológica, etc. -, isto é, por via da qual aos trabalhadores deixa de ser evidente a relação de produção que aí se encobre. Se a relação é apenas uma "coisa" (aqui considera-se a tecnologia), então é mais fácil pensá-la como algo "neutro" e numa simples mudança da sua utilização.

Os trabalhadores devem ultrapassar esse momento (certamente com o contributo da luta de classes e da respetiva consciencialização) ao transformar as relações sociais que estão na base da sua subjugação e do referido encobrimento ${ }^{41}$. Pois concentrar baterias em exclusivo no desenvolvimento da tecnologia acaba por ser uma manifestação de "feitiço", desconhecimento, "esquecimento", das relações sociais que a embasam.

Em jeito de arremate final, serve ainda uma passagem que se encontra mais ou menos a meio do $13 .^{\circ}$ capítulo, o capítulo de Das Kapital que guiou a presente exposição:

38 A atribuição de um "determinismo tecnológico" a Marx geralmente vem acompanhada de uma rotulagem "mecanicista" e "unilateral", quase sempre carregada de um sentido "fatalista", na verdade, alheia ao autor, mas assim atribuída por via de uma rejeição ou incompreensão do papel da dialética na sua conceção.

39 Ainda que a "revolução tecnológica" atual possa ser considerada como inevitável, em nada está garantido que esta tenha de se desenvolver (inevitavelmente) capturada pelas leis do capital, bem como, por exemplo, se a tecnologia se desenvolvesse "naturalmente", então, não precisaria de outros fatores para permitir a diminuição do dia de trabalho (por exemplo, greves), isso se daria por si só, o que não é o que acontece.

$40 \mathrm{O}$ que contradiz a generalidade do pensamento reformista, de diverso jaez, que busca sempre o "lado bom" da tecnologia por via de um suposto e gradual combate ao "lado mau" do sistema, sem pretender fazer o que quer que seja acerca das suas próprias contradições (cf. por exemplo, MARX, 1847). Pode, ainda, ser acrescentada toda a questão relativa às insolvências bancárias mais recentes e a maneira como facilmente se apelidou parte das suas atividades como correspondentes a um "banco mau" e as que, porventura, ainda logravam "salvação", como "banco bom". Assim, descurando a conexão entre umas atividades e outras, dadas as relações de gestão capitalistas.

${ }^{41} \mathrm{O}$ apelo de Marx, com vista à superação do "místico véu de nevoeiro", segue no sentido de um controlo consciente e planificado da produção social (cf. 1867: 93-94). Para um exemplo de "feiticismo" (tecnologista) atual, podemos remeter para o geral das conceções dos teóricos neoschumpeterianos (cf. SMITH, 2004: 230-231).

ANTUNES, Paulo Fernando Rocha. Marx, maquinaria e grande indústria: o desenvolvimento tecnológico no Livro I de Das Kapital. Griot : Revista de Filosofia, Amargosa, Bahia, v.16, n.2, p.36-55, dezembro/2017. 
É preciso tempo e experiência para que o operário [mas podem ser igualmente os restantes assalariados, entre outros] aprenda a distinguir a maquinaria [pesada, mas, seguramente, também digital, entre outras] da sua utilização [aplicação] capitalista e a dirigir os seus ataques não contra os próprios meios materiais de produção [e restantes parceiros de classe], mas contra a sua forma social de exploração (1867: 452) ${ }^{42}$.

42 «Es bedarf Zeit und Erfahrung, bevor der Arbeiter die Maschinerie von ihrer kapitalistischen Anwendung unterscheiden und daher seine Angriffe vom materiellen Produktionsmittel selbst auf dessen gesellschaftliche Exploitationsform übertragen lernt.» Já se sabe que as expressões “utilização", “aplicação", no sentido de Marx aqui presente não têm qualquer sentido "neutral”.

ANTUNES, Paulo Fernando Rocha. Marx, maquinaria e grande indústria: o desenvolvimento tecnológico no Livro I de Das Kapital. Griot : Revista de Filosofia, Amargosa, Bahia, v.16, n.2, p.36-55, dezembro/2017. 


\section{Referências bibliográficas:}

ADLER, Paul S. "Technological Determinism". In: CLEGG, Stewart; BAILEY James R. (eds.). International Encyclopedia of Organization Studies, 2007. Acedido a 13 de maio de 2017, disponível em: http://dx.doi.org/10.4135/9781412956246.n530.

ALCHIAN, Armen; ALLEN, William R. Exchange and Production. Competition, Coordination, and Control. $3^{\text {rd }}$ ed. Belmont, California: Wadsworth Publishing Company, 1983 (1964).

AXELOS, Kostas. Alienation, Praxis, and Techné in the Thought of Karl Marx. Translated by Ronald Bruzina. Austin-London: University of Texas Press, 1976 (Marx, penseur de la technique: De l'aliénation de l'homme à la conquête du monde, 1961).

BARATA-MOURA, José. Ontologia e Política. Estudos em torno de Marx - II. Lisboa: Edições «Avante!», 2016.

BIMBER, Bruce. "Karl Marx and the Three Faces of Technological Determinism". Social Studies of Science, SAGE, London, Newbury Park and New Delhi, vol. 20, pp. 333-51, 1990.

BOOTH, Adam. "Universal basic income: utopian dream or libertarian nightmare?". In Defense of Marxism. 10 February, 2017. Acedido a 13 de maio de 2017, disponível em: https:/www.marxist.com/universal-basic-income-utopiandream-or-libertarian-nightmare.htm.

BRYNJOLFSSON, Erik; McAFEE, Andrew. The Second Machine Age: Work, Progress, and Prosperity in a Time of Brilliant Technologies. New York: W. W. Norton \& Company, 2014.

DIÉGUEZ, Antonio. "El determinismo tecnológico: indicaciones para su interpretación". Argumentos de Razón Técnica, 8, pp. 67-87, 2005.

DUSSEL, Enrique. Towards an Unknown Marx. A Commentary on the Manuscripts of 1861-63. Translated by Yolanda Angulo. London-New York: Routledge, 2001 (Hacia un Marx desconocido. Un comentario de los Manuscritos del 61-63, 1988).

EATWELL, John. "Socially necessary technique". EATWELL, John; MILGATE, Murray; NEWMAN, Peter, eds. Marxian Economics. London and Basingstoke: The Macmillan Press Limited, 1990; pp. 342-343.

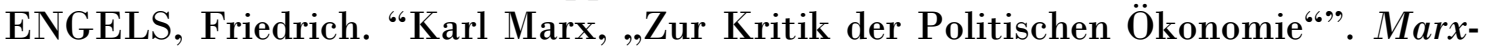
Engels Werke (Doravante: MEW). Berlin: Dietz Verlag, 1961 (1859); vol. 13, pp. 468477.

Die Entwicklung des Sozialismus von der Utopie zur Wissenschaft. In: MEW, 1987 (1880); vol. 19, pp. 181-228.

. Vorwort zum „Manifest der Kommunistischen Partei” (deutsche Ausgabe von 1883). MEW, 1962 (1883); vol. 21, pp. 3-4.

. "Vorwort zur englischen Ausgabe". In: MARX, Karl. Das Kapital. Kritik der politischen Ökonomie. MEW, 1962 (1886); vol. 23, pp. 36-40.

FEENBERG, Andrew. "Marxism and the Critique of Social Rationality: From Surplus Value to the Politics of Technology". Cambridge Journal of Economics, vol. $34,{ }^{\circ} .1$, pp. 37-49, 2010.

KATZ, Claudio "La concepción marxista del cambio tecnológico". Revista Buenos Aires. Pensamiento económico, n. ${ }^{\circ}$ 1, otoño, Buenos Aires, 1996.

ANTUNES, Paulo Fernando Rocha. Marx, maquinaria e grande indústria: o desenvolvimento tecnológico no Livro I de Das Kapital. Griot : Revista de Filosofia, Amargosa, Bahia, v.16, n.2, p.36-55, dezembro/2017. 53 
"Discusiones marxistas sobre tecnologia". Razón y Revolución, n. ${ }^{\circ}$, invierno, reedición electrónica, 1997.

"Determinismo tecnológico y determinismo histórico-social". Redes, vol. V, n. ${ }^{\circ} 11$, junio, pp. 37-52, 1998.

MANDEL, Ernest. "Introduction". In: MARX, Karl. Capital: A Critique of Political Economy. Translated by Ben Fowkes. London: Penguin, 1990; vol. 1, pp. 11-86.

MARX, Karl-ENGELS, Friedrich. Die deutsche Ideologie. Kritik der neuesten deutschen Philosophie in ihren Repräsentanten Feuerbach, B. Bauer und Stirner, und des deutschen Sozialismus in seinen verschiedenen Propheten. MEW, 1978 (1845); vol. 3, pp. 9-530.

MARX, Karl. Misère de la philosophie: Réponse à la Philosophie de la misère de M. Proudhon. Paris: Éditions Sociales, 1968 (1847). Lohnarbeit und Kapital. MEW, 1961 (1849); vol. 6, pp. 397-423.

. Cuaderno tecnológico-histórico. Estudio prelimar de Enrique Dussel. México: Universidad Autónoma de Puebla, 1984 (1851).

Der achtzehnte Brumaire des Louis Bonaparte. MEW, 1960 (1852); vol. 8, pp. 111-207.

Grundrisse der Kritik der politischen Ökonomie. MEW, 1983 (1857-58); vol. 42.

Economic manuscript of 1861-63. In: Marx and Engels Collected Works. London: Lawrence \& Wishart, 1988 (1861-63); vol. 30, pp. 9-451.

Das Kapital. Kritik der politischen Ökonomie. MEW, 1962 (1867); vol. 23 (O Capital. Crítica da Economia Política. Tradução de José Barata-Moura et al. Moscovo-Lisboa: Edições Progresso-Edições «Avante!», 1990-1997; livro I, tomo 1$3)$.

Kritik des Gothaer Programms, MEW, 1987 (1875); vol. 19, pp. 11-32.

MOHUN, Simon. "Labour process". In: BOTTOMORE, Tom, ed.. A Dictionary of Marxist thought. $2^{\text {nd }}$ ed. Oxford: Blackwell Publishers, Ltd., 2001 (1983a) (reprinted); pp. 297-301.

"Machinery and machinofacture". In: BOTTOMORE, Tom, ed. A Dictionary of Marxist thought. 2nd ed. Oxford: Blackwell Publishers, Ltd., 2001 (1983b) (reprinted); pp. 331-332.

MORO, Domenico. A Crise do Capitalismo e Marx. Resumo de O Capital com referência ao século XXI. Tradução de José Oliveira. Lisboa: Página a Página, 2016 (Nuovo compendio del Capitale. Sintesi del I libro del Capitale di K. Marx con riferimenti e confronti con la realtà contemporânea, 2006).

MURRAY, Patrick. "The Social and Material Transformation of Production by Capital: Formal and Real Subsumption in Capital". In: BELLOFIORE, Riccardo; TAYLOR, Nicola (eds.). The Constitution of Capital. Essays on Volume I of Marx's Capital. Basingstoke: Palgrave McMillan, 2004; pp. 243-273.

PERELMAN, Michael. Class Warfare in the Information Age. New York: St Martin's Press, 1998.

ROPOHL, Günter. "A Critique of Technological Determinism". In: DURBIN, Paul T.; RAPP, Friedrich (eds.). Philosophy and Technology. Dordrecht: D. Reidel Publishing Company, 1983; pp. 83-96.

ANTUNES, Paulo Fernando Rocha. Marx, maquinaria e grande indústria: o desenvolvimento tecnológico no Livro I de Das Kapital. Griot : Revista de Filosofia, Amargosa, Bahia, v.16, n.2, p.36-55, dezembro/2017. 54 
SHAW, William H. Marx's Theory of History. Stanford, California: Standford University Press, 1978.

SMITH, Tony. Technology and Capital in the Age of Lean Production. A Marxian Critique of the 'New Economy'. Albany: State University of New York Press, 2000. "Technology and History in Capitalism: Marxian and Neo-Schumpeterian Perspectives". In: BELLOFIORE, Riccardo; TAYLOR, Nicola (eds.). The Constitution of Capital. Essays on Volume 1 of Marx's Capital. Basingstoke: Palgrave McMillan, 2004; pp. 217-242. . "The Chapters on Machinery in the 1861-63 Manuscripts". In: BELLOFIORE, Riccardo; FINESCHI, Roberto (eds.). Re-reading Marx. New Perspectives after the Critical Edition. Basingstoke: Palgrave McMillan, 2009; pp. 112127.

STEIN, Ben. "In Class Warfare, Guess Which Class Is Winning". The New York Times, 2006. November 26. Acedido a 13 de maio de 2017, disponível em: http://www.nytimes.com/2006/11/26/business/yourmoney/26every.html.

WARSH, David. Knowledge and the Wealth o $f$ Nations: A Story o $f$ Economic Discovery. New York: W. W. Norton, 2006.

WARTENBERG, Thomas E. Thinking on Screen. Film as Philosophy. London-New York: Routledge, Taylor\&Francis Group, 2007.

WOOD, Ellen M. Democracy Against Capitalism: Renewing Historical Materialism. Cambridge: Cambridge University Press, 1995.

YOUNG, Robert M. "Technology". In: BOTTOMORE, Tom, ed. A Dictionary of Marxist thought. $2^{\text {nd }}$ ed. Oxford: Blackwell Publishers, Ltd., 2001 (1983) (reprinted); p. 535.

Autor(a) para correspondência: Paulo Fernando Rocha Antunes, Faculdade de Letras da Universidade de Lisboa, Alameda da Universidade, 1600-214 Lisboa, Portugal. pauloantunes@campus.ul.pt

ANTUNES, Paulo Fernando Rocha. Marx, maquinaria e grande indústria: o desenvolvimento tecnológico no Livro I de Das Kapital. Griot : Revista de Filosofia, Amargosa, Bahia, v.16, n.2, p.36-55, dezembro/2017. 55 